\title{
Expression of P-glycoprotein in HeLa cells confers resistance to ceramide cytotoxicity
}

\author{
JACQUELINE V. CHAPMAN, VALÉRIE GOUAZÉ-ANDERSSON and MYLES C. CABOT \\ John Wayne Cancer Institute at Saint John's Health Center, Santa Monica, CA 90404, USA
}

Received July 9, 2010; Accepted August 16, 2010

DOI: 10.3892/ijo_00000813

\begin{abstract}
The role of glucosylceramide synthase (GCS) in regulating ceramide-induced apoptosis has been widely studied. The purpose of this investigation was to evaluate the role of $\mathrm{P}$-glycoprotein $(\mathrm{P}-\mathrm{gp})$ in regulating ceramide cytotoxicity by using $\mathrm{C}_{6}$-ceramide. To accomplish this, we employed HeLa cells with conditional expression of the multidrug resistance gene 1/P-gp. HeLa cells expressing P-gp (P-gp/on cells) challenged with $\left[{ }^{14} \mathrm{C}\right] \mathrm{C}_{6}$-ceramide $(6 \mu \mathrm{M})$, synthesized 4.5 -fold the amount of $\mathrm{C}_{6}$-glucosylceramide (GC) compared to HeLa cells with suppressed expression of $\mathrm{P}-\mathrm{gp}$ (P-gp/off cells), whereas the generated levels of $\mathrm{C}_{6^{-}}$ sphingomyelin were almost equal (33 and $29 \%$ of intracellular ${ }^{14} \mathrm{C}$, respectively). Tamoxifen, a P-gp antagonist, decreased the $\mathrm{C}_{6}$-GC levels from $3.5-1.0 \%$ in the P-gp/off and from $17-2.8 \%$ of the total lipid ${ }^{14} \mathrm{C}$ levels in the $\mathrm{P}$-gp/on cells. Tamoxifen did not inhibit cell-free $\mathrm{C}_{6}-\mathrm{GC}$ synthesis in the P-gp/off or P-gp/on homogenates. However, a specific GCS inhibitor, ethylenedioxy-1-phenyl-2-hexadecanoylamino-3-pyrrolidino-1-propanol (ethylenedioxy-P4), blocked synthesis by $90 \%$. In the cytotoxicity assays, the P-gp/off cells were sensitive to $\mathrm{C}_{6}$-ceramide and the $\mathrm{P}$-gp/on cells were resistant. Resistance to $\mathrm{C}_{6}$-ceramide in the $\mathrm{P}$-gp/on cells was reversed by tamoxifen but not by ethylenedioxy-P4. Experiments in another cervical cancer model showed that
\end{abstract}

Correspondence to: Dr Myles C. Cabot, Department of Experimental Therapeutics, John Wayne Cancer Institute at Saint John's Health Center, 2200 Santa Monica Blvd., Santa Monica, CA 90404, USA

E-mail: cabot@jwci.org

Abbreviations: GCS, glucosylceramide synthase; GC, glucosylceramide; P-gp, P-glycoprotein; 4-HPR, fenretinide; MDR1, multidrug resistance gene 1; MDR multidrug resistance; FBS, fetal bovine serum; ethylenedioxy-P4, ethylenedioxy-1-phenyl-2hexadecanoylamino-3-pyrrolidino-1-propanol; SM, sphingomyelin; TLC, thin-layer chromatography; LSC, liquid scintillation counting; PPMP, 1-phenyl-2-hexadecanolamino-3-morpholino-1-propanol; PDMP, 1-phenyl-2-decanoylamino-3-morpholino-1-propanol

Key words: ceramide, P-glycoprotein, glucosylceramide, HeLa cells, $\mathrm{C}_{6}$-ceramide multidrug-resistant P-gp-rich KB-V1 cells synthesized 3-fold more $\mathrm{C}_{6}$-GC from $\mathrm{C}_{6}$-ceramide than the parental, $\mathrm{P}$-gp-poor KB-3-1 cells, and whereas tamoxifen had no effect on the $\mathrm{C}_{6}$ GC synthesis in the KB-3-1 cells, it inhibited synthesis by $70 \%$ in the KB-V1 cells. This study demonstrates that P-gp potentiates $\mathrm{C}_{6}$-ceramide glycosylation and if antagonized augments $\mathrm{C}_{6}$-ceramide sensitivity, both features previously ascribed to GCS. We propose that P-gp can be an effective target for enhancing short-chain ceramide cytotoxicity in the treatment of drug-resistant cancer.

\section{Introduction}

This study is aimed at defining the role of P-glycoprotein (P-gp) in ceramide metabolism in order to determine whether $\mathrm{P}$-gp, as opposed to glucosylceramide synthase (GCS). would be a more efficacious target for amplifying ceramide sensitivity. Rather than generating ceramide endogenously, we employed a short-chain, cell-permeable ceramide analog, $\mathrm{C}_{6}$-ceramide. Apoptosis is now recognized as a cellular mechanism linked to the cytotoxic response provoked by a myriad of anti-cancer agents $(1,2)$. Studies have shown that the generation of intracellular ceramide mediates the induction of apoptosis in cancer cells (3-5). Due to the role of ceramide in tumor cell response to cytotoxic anti-cancer agents (6), the intracellular mechanisms that regulate ceramide metabolism are important and have become the object of considerable study $(4,7)$. For example, the modification of ceramide metabolism can enhance cancer cell and tumor sensitivity to cytotoxics, including chemotherapy drugs (8-12). GCS has been the focus of many such studies on ceramide clearance (13). Also, GCS catalyzes the conversion of ceramide to glucosylceramide (GC).

We previously demonstrated that multidrug-resistant cell lines and tumor specimens from patients who had failed chemotherapy, contained elevated levels of GC $(14,15)$. Consequently, we postulated that the capacity of multidrugresistant cancer cells to glycosylate ceramide could be a mechanism of cellular resistance to agents that induce ceramide formation, e.g. anthracyclines $(16,17)$, and fenretinide (4-HPR) (18). Subsequent study showed that structurally diverse P-gp antagonists such as tamoxifen, verapamil, and cyclosporin A, inhibited GC synthesis in multidrug-resistant cancer cells (19). This observation was supported by De Rosa et al (20) in a study using cyclosporin A and ketoconazole in P-gp-containing cell lines. Furthermore, the 
study of Shabbits and Mayer (21) demonstrated that P-gp can modulate cellular sensitivity to endogenously generated longchain ceramide in response to taxane exposure.

It is well known that P-gp acts as a flipase for glycosphingolipids including GC (22). Other ABC transporters also show specificity for lipid translocation $(23,24)$. In order to assess the roles of GCS and P-gp in regulating ceramide sensitivity, we employed a HeLa cell line transfected with human multidrug resistance gene 1 (MDR1) whose MDR1/ P-gp status could be repressed by the removal of colchicine and the addition of tetracycline (25). This provided us with a model in which the only variable was the status of P-gp, and it eliminated a myriad of changes that accompany cells under the selective pressure of chemotherapy. Here we demonstrate that i) P-gp is a driving force behind the conversion of shortchain ceramide to short-chain GC when GCS is challenged with $\mathrm{C}_{6}$-ceramide, ii) that $\mathrm{P}$-gp antagonists, such as tamoxifen (26-28) inhibit GC synthesis at P-gp but not at GCS, and iii) that the resistance of $\mathrm{P}$-gp-expressing cells to $\mathrm{C}_{6}$-ceramide is reversible by antagonizing $\mathrm{P}-\mathrm{gp}$, and not by inhibiting GCS. In the realm of AML leukemia, colorectal and ovarian cancer, where multidrug resistance (MDR) proteins are widely expressed regardless of treatment history or stage of disease, the employment of P-gp antagonists as sensitizers of short-chain ceramides could have clinical utility.

\section{Materials and methods}

Materials. We purchased $\left[{ }^{3} \mathrm{H}\right] \mathrm{UDP}-$ glucose $(40 \mathrm{Ci} / \mathrm{mmol})$, $\left[9,10-{ }^{3} \mathrm{H}(\mathrm{N})\right]$ palmitic acid $(60 \mathrm{Ci} / \mathrm{mmol})$, and $\mathrm{L}-\left[{ }^{3} \mathrm{H}(\mathrm{G})\right]$ serine (25 Ci/mmol) from American Radiolabeled Chemicals, Inc. (St. Louis, MO). $\left[{ }^{3} \mathrm{H}\right]$ Vinblastine sulfate $(2.1 \mathrm{Ci} / \mathrm{mmol})$ was from Moravek Biochemicals, Inc. (Brea, CA). $\left[1-{ }^{14} \mathrm{C}\right] \mathrm{C}_{6^{-}}$ ceramide ( $\mathrm{N}\left[1-{ }^{14} \mathrm{C}\right]$ hexanoyl-sphingosine), a gift from $\mathrm{Dr}$ Alicja Bielawska, at the Medical University of South Carolina, Charleston, SC, was synthesized as previously described (29). We also utilized N-hexanoyl[1- $\left.{ }^{14} \mathrm{C}\right]-\mathrm{D}-$ erythro-sphingo-sine $(55 \mathrm{mCi} / \mathrm{mmol}$; American Radiolabeled Chemicals, Inc.). The GCS inhibitor ethylenedioxy-1phenyl-2-hexadeca-noylamino-3-pyrrolidino-1-propanol (ethylenedioxy-P4) (30), a phenyl ring substituted analog of parent P4, D-threo-1-phenyl-2-hexadecanoylamino-3pyrrodilino-1-propanol, was a gift from Dr James Shayman, at the University of Michigan, Ann Arbor, MI. $\mathrm{C}_{6}$-ceramide, D-erythro-sphingo-sine, glucosyl- $\mathrm{C}_{8}$-ceramide (D-glucosylB-1-1'-N-octanoyl-D-erythro-sphingosine), L- $\alpha$-phosphatidylcholine (dioleoyl), and brain sulfatide, ammonium salt, were purchased from Avanti Polar Lipids, Inc. (Alabaster, AL). Short-chain sphingomyelin (SM), Nhexanoyl-sphingosylphosphorylcholine $\left(\mathrm{C}_{6}\right)$, was from Matreya (Pleasant Gap, PA). Tamoxifen (citrate and $\mathrm{HCl}$ were used), verapamil, Rhodamine 123, and cyclosporine A were purchased from Sigma-Aldrich (St. Louis). The monoclonal antibody, C219, against human P-gp was a product of Calbiochem (San Diego, CA). Silica Gel G prescored thinlayer chromatography (TLC) plates were purchased from Analtech (Newark, DE), and ACS or HPLC grade certified solvents were purchased from Fisher Scientific. EcoLume liquid scintillation cocktail was purchased from ICN (Costa Mesa, CA).
Cell lines. The HeLa cell model was kindly provided by $\mathrm{Dr}$ Michael Gottesman, at the National Cancer Institute, Bethesda, MD. We designated the P-gp/on cells as HeLa cells expressing P-gp and the P-gp/off cells as HeLa cells with down-regulated P-gp expression. The HeLa P-gp/on cells were maintained as described previously (25) in DMEM/high glucose medium (Life Technologies), with 10\% tetracycline-approved fetal bovine serum (FBS) from Hyclone (Logan, UT), $20 \mathrm{ng} / \mathrm{ml}$ colchicine, and $2 \mathrm{mM} \mathrm{L}-$ glutamine. In order to obtain P-gp/off cells, P-gp/on cells were switched to colchicine-free, tetracycline-containing ( $2 \mu \mathrm{g} / \mathrm{ml}$ ) medium for 3-4 days to deplete P-gp expression.

KB-3-1, the human cervical cancer cell line and its multidrug-resistant counterpart, KB-V1, were maintained as previously described (31) in DMEM/high glucose medium with 10\% FBS (Hyclone). These cells were generously provided by Dr Michael Gottesman. The medium for KB-V1 cells also contained vinblastine $(1.0 \mu \mathrm{g} / \mathrm{ml})$.

Cell supplements. $\left[{ }^{14} \mathrm{C}\right] \mathrm{C}_{6}$-ceramide and unlabeled $\mathrm{C}_{6}$-ceramide were dissolved in ethanol and added to the culture medium. The ethanol concentration was kept constant within the experiments and ranged between $0.05-0.2 \%$. Ethanol was also the vehicle for ethylenedioxy-P4, tamoxifen, verapamil and cyclosporin A. Culture medium was used to dissolve tetracycline and colchicine.

Western blot analysis. The P-glycoprotein was detected by Western blot analysis using C219 monoclonal antibody as previously described (32).

Cell-free GCS assay. GCS activity was measured as described previously (33) using the $100,000 \mathrm{x}$ g membrane fraction isolated from the various cell lines. This method is a modification of the procedure described by Shulka and Radin (34). The enzyme assay containing $50 \mu \mathrm{g}$ of microsomal protein, in a final volume of $0.2 \mathrm{ml}$, was performed in a shaking water bath at $37^{\circ} \mathrm{C}$ for $60 \mathrm{~min}$. The reaction contained liposomal substrate composed of $\mathrm{C}_{6}$-ceramide $(1.0 \mathrm{mM})$, phosphatidylcholine (3.6 mM) and brain sulfatides $(0.9 \mathrm{mM}$; molecular weight, 563). The liposomal substrate was prepared by mixing the components, evaporating the solvents under a stream of nitrogen, and sonicating in water over ice for $1 \mathrm{~min}$ using a microtip at $50 \%$ output (Kontes Micro Ultrasonic Cell Disrupter). Other reaction components included sodium phosphate buffer $(0.1 \mathrm{M})$, pH 7.8, EDTA (2.0 mM), $\mathrm{MgCl}_{2}$ $(10 \mathrm{mM})$, dithiothreitol $(1.0 \mathrm{mM}), \beta$-nicotinamide adenine dinucleotide $(2.0 \mathrm{mM})$ and $\left[{ }^{3} \mathrm{H}\right] \mathrm{UDP}$-glucose $(0.5 \mathrm{mM})$. Radiolabeled and unlabeled UDP-glucose were diluted to achieve the desired radiospecific activity (4700 dpm/nmol). In order to terminate the reaction, tubes were placed on ice, and $0.5 \mathrm{ml}$ isopropanol and $0.4 \mathrm{ml} \mathrm{Na} \mathrm{SO}_{4}$, were added. After brief vortex mixing, $3 \mathrm{ml} t$-butyl methyl ether was added, and tubes were mixed for $30 \mathrm{sec}$. After centrifugation, $0.5 \mathrm{ml}$ of the upper phase, which contained GC, were withdrawn and mixed with $4.5 \mathrm{ml}$ of EcoLume for the analysis of radioactivity by liquid scintillation counting (LSC).

Lipid analysis. Total cellular lipids were extracted as described previoulsy (33). After the nitrogen evaporation of the chloro- 
form lower phase of the biphasic extraction, radiolabeled lipids were taken up in $200 \mu \mathrm{l}$ chloroform/methanol $(2: 1, \mathrm{v} / \mathrm{v})$ and a $5 \mu 1$ aliquot was sampled for radioactivity by LSC. This sampling was used to calculate uptake and recoveries. The solvent was again evaporated, $50 \mu 1$ chloroform/ methanol were added and $10 \mu 1$ of this were applied to the origin of the TLC plate. Lipids were resolved using a solvent system containing chloroform/methanol/acetic acid/water $(65: 25: 2: 2, v / v)$ or a slight variation there of, in filter paperlined tanks. Two other solvent systems were employed to verify results: Chloroform/methanol/ammonium hydroxide (70:30:4, v/v) and chloroform/methanol/water (60:40:8, v/v). These chromatography systems resolved $\mathrm{C}_{6}$-ceramide, $\mathrm{C}_{6}$-GC, and $\mathrm{C}_{6}$-SM. After separation, the lipids were visualized in iodine vapor by co-migration with commercial standards. The areas of interest were scrapped and radioactivity was quantitated by LSC (35).

Cell viability assay. Cell viability was determined using the Cell Titer 96 Aqueous One Solution kit from Promega (Madison, WI). Absorbance at $490 \mathrm{~nm}$ was recorded with a Microplate Fluorescent Reader FL600, BioTek Instruments, Inc. (Winooski, VT).

mRNA quantitation. For MDR1, real-time quantitative PCR analysis was done using primers and probe sequences as previously described (32). Primer sequences for GCS (Invitrogen, Carlsbad, CA) were as follows: GCS labeled 5'CGATTACTGCCTTCTTCTTGTTGAGGTGTAAT FAM-3', and GCS unlabeled 5'-TCTTCTTGGTGCTGTGGCTGAT-3'. Human $B$-actin was used as the endogenous control. SuperScript III Platinum One-Step qRT-PCR kits (Invitrogen, Chicago, IL) were employed for the assays. Analysis was carried out on a Rotor-Gene 3000 (Corbett Research, Sydney, Australia).

Uptake and efflux of $\left[{ }^{14} \mathrm{C}\right] \mathrm{C}_{6}$-ceramide. $\mathrm{P}$-gp/on cells were seeded in 6-well plates $(400,000 /$ well $)$ and exposed the following day to $6.0 \mu \mathrm{M}\left[{ }^{14} \mathrm{C}\right] \mathrm{C}_{6}$-ceramide $(84,000 \mathrm{dpm})$ for $4 \mathrm{~h}$ in the absence and presence of verapamil $(5.0 \mu \mathrm{M})$. Samples of washed cells, lysed in $0.1 \%$ sodium dodecylsulfate, were then assessed for the uptake of radioactivity by LSC. Companion cultures at the end of the 4-h uptake period were washed twice with fresh medium and re-incubated for $90 \mathrm{~min}$ in the absence and presence of verapamil. The medium was then sampled by LSC to evaluate the efflux.

Vinblastine uptake. The cells (P-gp/on) were seeded in 12well plates $\left(50,000\right.$ cells/well) and the $\left[{ }^{3} \mathrm{H}\right]$ vinblastine uptake was measured in the absence and presence of tamoxifen, verapamil, or cyclosporin A (all at $10 \mu \mathrm{M}$ ) following the method used by Ohnishi et al (36).

\section{Results}

We first established the utility of the tet-repressible MDR1/ P-gp model for our purpose, which was to evaluate the role of P-gp in the regulation of ceramide metabolism and cytotoxicity in cancer cells compared to GCS. After the removal of colchicine and following the 3-day exposure of
$\mathrm{P}$-gp/on cells to tetracycline $(2.0 \mu \mathrm{g} / \mathrm{ml}$ medium $)$, MDR1 mRNA levels dropped $\sim 300$-fold, normalized to $\beta$-actin (data not shown). The down-regulation of P-gp by the removal of colchicine and the addition of tetracycline did not alter the levels of GCS mRNA (ratio of GCS to B-actin was 1.1 and 1.0 in P-gp/on and P-gp/off cells, respectively) (data not shown). The 3-day exposure to tetracycline was sufficient to bring P-gp down to largely undetectable levels, as shown by Western blot analysis (Fig. 1A). In order to determine the influence of $\mathrm{P}$-gp on $\mathrm{C}_{6}$-ceramide anabolism, the P-gp/off and $\mathrm{P}$-gp/on cells were exposed to $\left[{ }^{14} \mathrm{C}\right] \mathrm{C}_{6}$-ceramide, and the levels of intracellular $\left[{ }^{14} \mathrm{C}\right] \mathrm{C}_{6}-\mathrm{GC}$ and $\mathrm{C}_{6}-\mathrm{SM}$ were measured. Fig. 1B shows that the HeLa P-gp/on cells synthesized 4.4-fold more $\mathrm{C}_{6}$-GC compared to the P-gp/off cells. In the P-gp/on cells, $17 \%$ of total lipid ${ }^{14} \mathrm{C}$ was present in $\mathrm{C}_{6}$ - $\mathrm{GC}$, whereas in $\mathrm{P}$-gp/off cells $\left[{ }^{14} \mathrm{C}\right] \mathrm{C}_{6}-\mathrm{GC}$ accounted for only $3 \%$ of the total lipid radioactivity. As shown in Fig. $1 \mathrm{C}$, the amount of $\mathrm{C}_{6}-\mathrm{SM}$ synthesized from $\mathrm{C}_{6}$-ceramide in the $\mathrm{P}$-gp/on and $\mathrm{P}$-gp/off cells was almost identical. Thus, whereas P-gp affected an increase in the synthesis of $\mathrm{C}_{6}-\mathrm{GC}$, it had no influence on the generation of $\mathrm{C}_{6}-\mathrm{SM}$ from $\mathrm{C}_{6}$-ceramide.

Tamoxifen inhibits long-chain GC synthesis in various human cancer cell lines $(19,37,38)$. The addition of tamoxifen blocked the conversion of $\mathrm{C}_{6}$-ceramide to $\mathrm{C}_{6}$ - $\mathrm{GC}$ by 78 and $86 \%$ in the $\mathrm{P}$-gp/off and $\mathrm{P}$-gp/on cells, respectively (Fig. 1B, crosshatch). Taking into account the high amount of $\mathrm{C}_{6}$ ceramide that was converted to $\mathrm{C}_{6}$-GC in the $\mathrm{P}$-gp/on cells $\left(17 \%\right.$ of total intracellular $\left.{ }^{14} \mathrm{C}\right)$, the tamoxifen addition imparted a 7.2-fold decrease in the overall synthesis. In order to determine whether the inhibition of the $\mathrm{C}_{6}$ - $\mathrm{GC}$ synthesis by tamoxifen required intact cells and to assess whether tamoxifen inhibits GCS, we evaluated the effects of tamoxifen and that of a known, specific chemical inhibitor of GCS, ethylenedioxy-P4, on cell-free GCS activity. In these experiments, the high-speed GCS-containing membrane fraction was isolated from the $\mathrm{P}$-gp/off and $\mathrm{P}$-gp/on cells and incubated with $\left[{ }^{3} \mathrm{H}\right] \mathrm{UDP}$-glucose, $\mathrm{C}_{6}$-ceramide and cofactors, as detailed in Methods. The tamoxifen addition to the P-gp/on cell-free incubations did not inhibit GCS activity (16.0 \pm 0.9 vs. $19.4 \pm 3.1 \mathrm{nmol} \mathrm{C}$-GC synthesized $/ \mathrm{mg}$ protein $/ \mathrm{h}$, in the absence and presence of tamoxifen, respectively) (Fig. 2). In contrast, ethylenedioxy-P4 inhibited GCS activity by $88 \%$ in the $\mathrm{P}$-gp/on lysates, compared to the $\mathrm{P}$-gp/on control lysates. Lastly, cell-free GCS activity was $30 \%$ higher in the P-gp/off lysates compared to the P-gp/on cell lysates (Fig. 2, grey bars).

Verapamil and cyclosporine A were also investigated to determine if other P-gp antagonists could inhibit $\mathrm{C}_{6}$-GC synthesis in the $\mathrm{P}-\mathrm{gp} / \mathrm{on}$ cells. Tamoxifen was the most potent inhibitor of $\mathrm{C}_{6}$ - $\mathrm{GC}$ synthesis (75\% inhibition), whereas cyclosporin A $(5.0 \mu \mathrm{M})$ imparted $25 \%$ inhibition, and verapamil $(5.0 \mu \mathrm{M})$ had no influence (data not shown).

The experiments thus far demonstrate that intact cells expressing $\mathrm{P}$-gp have a heightened capacity to convert $\mathrm{C}_{6^{-}}$ ceramide to $\mathrm{C}_{6}-\mathrm{GC}$. However, when assessed in cell-free systems, $\mathrm{C}_{6}$-GC synthesis was similar in the lysates of the P-gp/off and P-gp/on cells (Fig. 2). In order to determine whether $\mathrm{P}$-gp could protect cells from $\mathrm{C}_{6}$-ceramide cyto- 

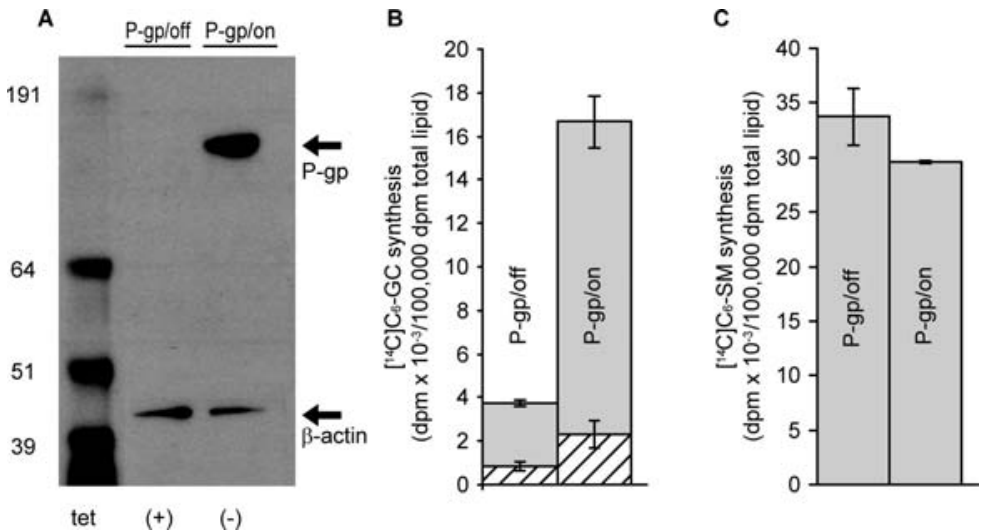

Figure 1. The effect of P-gp expression on $\mathrm{C}_{6}$-ceramide metabolism in HeLa cells and the influence of tamoxifen. (A) Conditional expression of P-gp. HeLa cells expressing P-gp (P-gp/on lane) were subcultured in colchicine-free medium containing tetracycline for 3 days (P-gp/off lane). P-gp was detected by Western blot analysis. Tet, tetracycline; col, colchicine. (B) Effect of P-gp status on the synthesis of $\mathrm{C}_{6}-\mathrm{GC}$ and the influence of tamoxifen. Cells, 1 day after seeding were exposed to $\left[{ }^{14} \mathrm{C}\right] \mathrm{C}_{6}$-ceramide $(6.0 \mu \mathrm{M})$ in the absence and presence of tamoxifen $(5 \mu \mathrm{M})$ for $24 \mathrm{~h} .\left[{ }^{14} \mathrm{C}\right] \mathrm{C}_{6}$-GC was quantitated as detailed in Methods. The crosshatch denotes the level of $\left[{ }^{14} \mathrm{C}\right] \mathrm{C}_{6}-\mathrm{GC}$ synthesis in the presence of tamoxifen. (C) Effect of P-gp status on the synthesis of $\mathrm{C}_{6}$-SM from $\mathrm{C}_{6}$-ceramide.

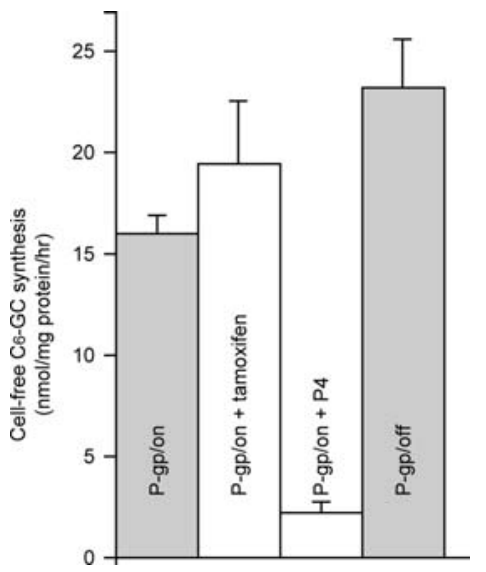

Figure 2. Cell-free GCS activity in HeLa cell homogenates and the effect of tamoxifen and ethylenedioxy-P4. High-speed $(100,000 \mathrm{x} \mathrm{g})$ membrane pellets were isolated from P-gp/on and P-gp/off cells, and GCS was assayed as previously described (34) with modifications (33). The reactions, containing $50 \mu \mathrm{g}$ microsomal protein, were incubated for $60 \mathrm{~min}$ at $37^{\circ} \mathrm{C}$ in a shaking water bath. Tamoxifen was present at $5.0 \mu \mathrm{M}$ and ethylenedioxy-P4, a specific GCS inhibitor, at $0.2 \mu \mathrm{M}$. Means $\pm \mathrm{SD}, \mathrm{n}=3$.

toxicity, the cells were exposed to $\mathrm{C}_{6}$-ceramide under various conditions. At the concentration tested, the P-gp/on cells were refractory to $\mathrm{C}_{6}$-ceramide cytotoxicity compared to the P-gp/off cells (Fig. 3A, plates 1, 2 and 5). However, the resistance to $\mathrm{C}_{6}$-ceramide cytotoxicity displayed in the $\mathrm{P}$-gp/ on cells was reversed by the addition of tamoxifen (Fig. 3A, plates 2-4). Thus, $\mathrm{C}_{6}$-ceramide partnered with tamoxifen is a lethal combination in these drug-resistant cells. Tamoxifen alone modified cell morphology and reduced cell growth (Fig. 3A, plates 1 and 3). In order to assess whether the inhibition of GCS could influence the sensitivity of the P-gp/ on cells to $\mathrm{C}_{6}$-ceramide, ethylenedioxy-P4 was added to the culture medium. Despite the strong inhibition of the $\mathrm{C}_{6}$-GC synthesis by ethylenedioxy-P4 (Fig. 3B), the inhibition of GCS failed to impact sensitivity to $\mathrm{C}_{6}$-ceramide in the P-gp/ on cells (Fig. 3A, plates 6 and 7). The results of cell viability assays confirmed that the inhibition of GCS with ethyle-
nedioxy-P4 was not effective in reversing the $\mathrm{C}_{6}$-ceramide resistance in the P-gp/on cells (Fig. 3C). These data clearly show that targeting P-gp is more effective than the inhibition of GCS for enhancing $\mathrm{C}_{6}$-ceramide cytotoxicity.

In order to rule out the possibility that the $\mathrm{C}_{6}$-ceramide resistance in the $\mathrm{P}$-gp/on cells was related to active efflux, we evaluated the uptake and efflux. The uptake of $\left[{ }^{14} \mathrm{C}\right] \mathrm{C}_{6}$ ceramide did not vary between the $\mathrm{P}$-gp/off and $\mathrm{P}$-gp/on cells. For example, at a dose of $6 \mu \mathrm{M}$, the P-gp/off and P-gp/ on cells took up 10 and $11 \%$ of the administered dose, respectively, after 24-h incubation. The addition of tamoxifen did not affect a change in uptake. Thus, tamoxifen does not influence the uptake or retention of $\mathrm{C}_{6}$-ceramide in either of the cell models. Similar experiments were conducted with verapamil using the $\mathrm{P}$-gp/on cells. Verapamil at a concentration of $5 \mu \mathrm{M}$ did not influence the uptake of $\left[{ }^{14} \mathrm{C}\right] \mathrm{C}_{6}$-ceramide over a 24-h period, and when the cells were washed free of radioactivity and re-incubated for $90 \mathrm{~min}$ in fresh medium, 59 and $57 \%$ of total cellular radioactivity was found in the medium in the absence and presence of verapamil, respectively.

In order to assess the chemotherapy efflux capacity in the $\mathrm{P}$-gp/on cells, we analyzed the influence of tamoxifen, verapamil, and cyclosporin A on the vinblastine uptake. All 3 antagonists were effective in retarding efflux and thus enhancing the intracellular levels of vinblastine (Fig. 4). Although it is well established that tamoxifen binds to and antagonizes P-gp (26-28), and that it has been administered in this capacity in clinical trials (39), it could be argued that tamoxifen is a substrate for P-gp (40). Therefore, we determined whether the true substrates of P-gp influenced $\mathrm{C}_{6}-\mathrm{GC}$ synthesis in $\mathrm{HeLa} \mathrm{P}$-gp/on cells. The results of the experiments using $\left[{ }^{14} \mathrm{C}\right] \mathrm{C}_{6}$-ceramide showed that Rhodamine 123 , a classical P-gp substrate, had no effect on $\mathrm{C}_{6}$-GC synthesis. These experiments demonstrate that $\mathrm{P}$-gp substrates do no attenuate the P-gp-governed production of $\mathrm{C}_{6}-\mathrm{GC}$.

Lastly, we evaluated $\mathrm{C}_{6}$-GC synthesis and the effect of tamoxifen in KB-3-1, a human cervical cancer cell line that is drug-sensitive and P-gp-poor, and in its multidrug-resistant 

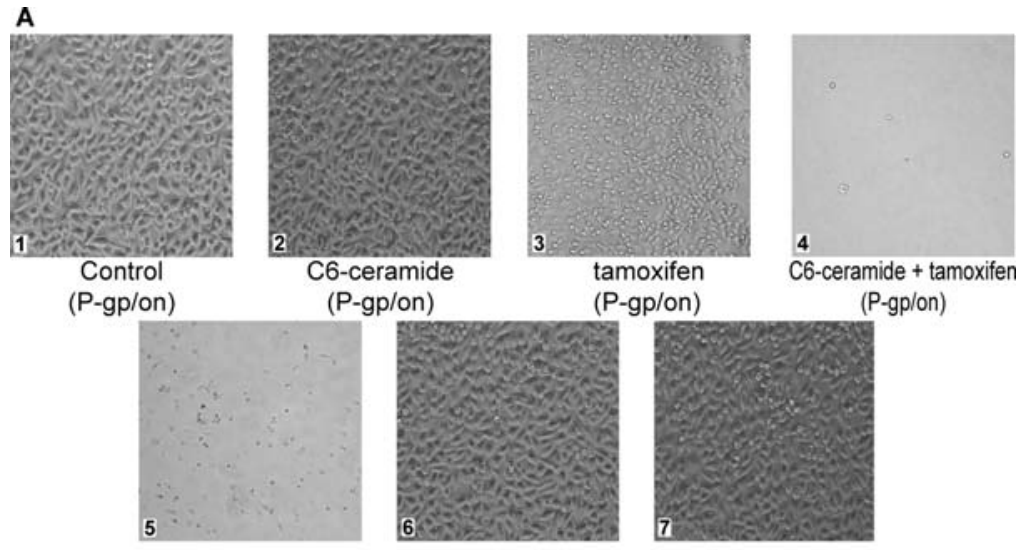

C6-ceramide

(P-gp/off)

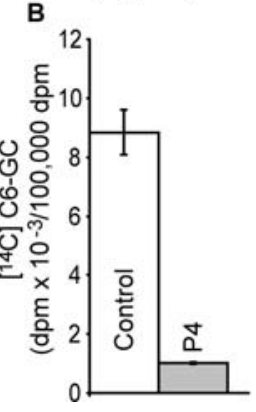

C6-ceramide + P4 (P-gp/on) (P-gp/on)

\section{C}

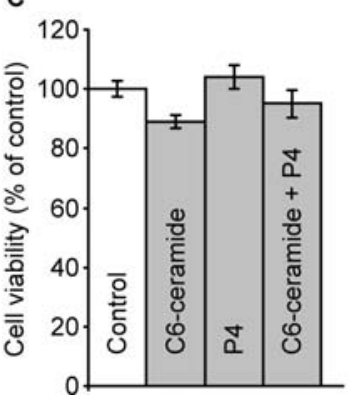

Figure 3. The influence of P-gp status on cell sensitivity to $\mathrm{C}_{6}$-ceramide and the effects of P-gp antagonists and GCS inhibitors on $\mathrm{C}_{6}$-ceramide cytotoxicity. (A) $\mathrm{C}_{6}$-ceramide sensitivity in P-gp/off and P-gp/on cells. Cells in 6-well plates were treated 1 day after seeding with the vehicle (control), tamoxifen (5 $\mu \mathrm{M}$ ), $\mathrm{C}_{6}$-ceramide $(3.75 \mu \mathrm{M})$, ethylenedioxy-P4 $(0.2 \mu \mathrm{M})$, or combinations indicated for $72 \mathrm{~h}$. Cell population density and morphology were captioned by photomicroscopy. P4, ethylenedioxy-P4. (B) Effect of ethylenedioxy-P4 on $\mathrm{C}_{6}$-GC synthesis in P-gp/on cells. Cells were grown in the absence (control) and presence of ethylenedioxy-P4 $(0.2 \mu \mathrm{M})$ for $24 \mathrm{~h}$ in medium containing $\left[{ }^{14} \mathrm{C}\right] \mathrm{C}_{6}$-ceramide $(4.0 \mu \mathrm{M})$. After lipid extraction, $\left[{ }^{14} \mathrm{C}\right] \mathrm{C}_{6}$ - $\mathrm{GC}$ was quantified by $\mathrm{TLC}$ and LSC. $\mathrm{n}=4$ wells \pm S.D. Experiments were repeated several times with similar results. (C) Effect of $\mathrm{C}_{6}$-ceramide and ethylenedioxy-P4 on P-gp/on cell viability. Cells, in 96-well plates, were grown with the vehicle (control), $\mathrm{C}_{6}$-ceramide $(4.0 \mu \mathrm{M})$, ethylenedioxy-P4 (0.2 $\left.\mu \mathrm{M}\right)$, or the combination for $72 \mathrm{~h}$, and cell viability was measured by MTS assay. $n=6 \pm$ S.D. Similar results were obtained after 24-h exposure to agents.

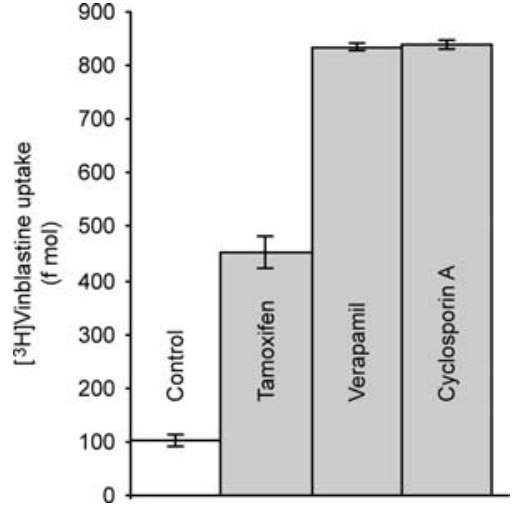

Figure 4. Effect of P-gp antagonists on vinblastine uptake in P-gp/on cells Cells $(50,000 /$ well) were seeded in 12-well plates. The following day the medium was replaced with $1 \%$ FBS medium and cells were exposed to the vehicle (control), tamoxifen, verapamil, or cyclosporin A (all at $10 \mu \mathrm{M}$ ) for $60 \mathrm{~min}$, after which $\left[{ }^{3} \mathrm{H}\right]$ vinblastine $(15.6 \mathrm{nM}$ final concentration) was added to each well and cells were incubated for $60 \mathrm{~min}$ and $37^{\circ} \mathrm{C}$. The uptake of vinblastine was determined as previously described (36).

counterpart, KB-V1, which expresses high levels of P-gp (31). When exposed to $\mathrm{C}_{6}$-ceramide, the $\mathrm{KB}-\mathrm{V} 1$ cells synthesized $\sim 3$-fold the amount of $\mathrm{C}_{6}$-GC compared to the KB-3-1 cells (Fig. 5). This confirms, using an alternate

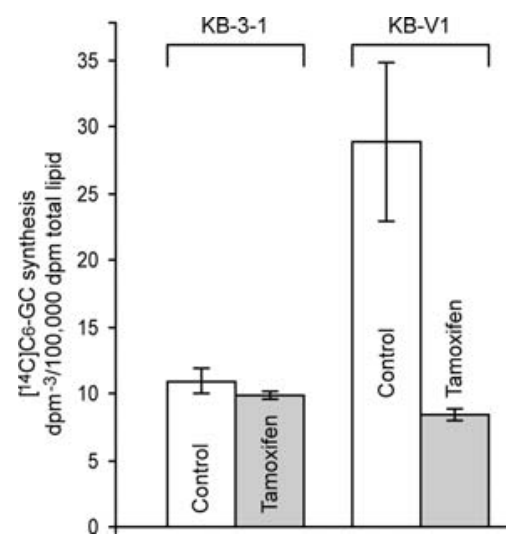

Figure 5. Metabolism of $\mathrm{C}_{6}$-ceramide in the KB-3-1 and KB-V1 cells and the influence of tamoxifen. Cells $(400,000 /$ well $)$ in 6-well plates were treated 1 day after subculture with the vehicle (control) or tamoxifen $(5 \mu \mathrm{M})$ in medium containing $4.0 \mu \mathrm{M}\left[{ }^{14} \mathrm{C}\right] \mathrm{C}_{6}$-ceramide for $24 \mathrm{~h}$. Synthesis of $\left[{ }^{14} \mathrm{C}\right] \mathrm{C}_{6}$ - $\mathrm{GC}$ was analyzed by LSC after the lipids were resolved by TLC.

model, that high P-gp expression confers heightened cellular capacity for ceramide glycosylation. Furthermore, whereas tamoxifen strongly depressed $\mathrm{C}_{6}$-GC synthesis in the $\mathrm{KB}-\mathrm{V} 1$ cells (70\% inhibition), it had little influence on $\mathrm{C}_{6}-\mathrm{GC}$ synthesis in the KB-3-1 cells (Fig. 5). 


\section{Discussion}

The glycosphingolipid translocase properties of P-gp and other ABC proteins (22-24) prompted our investigation of glycolipid synthesis in cells challenged with short-chain ceramide analogs, as these cell-permeable agents have been used extensively in studies on ceramide cytotoxicity and are candidates for clinical study $(41,42)$. Although multidrugresistant cancer cells expressing high levels of $\mathrm{P}-\mathrm{gp}$ have been employed in the majority of studies $(14,15,21,43,44)$, the present study marks the first time that the role of P-gp in ceramide metabolism and cytotoxicity has been evaluated by using cells with conditional expression of P-gp. This allowed for the clear assessment of the role of P-gp in modulating ceramide sensitivity. HeLa cells in the P-gp/on mode clearly converted more $\mathrm{C}_{6}$-ceramide to $\mathrm{C}_{6}-\mathrm{GC}$ compared to the $\mathrm{P}$-gp/ off cells (Fig. 1), as did the multidrug-resistant KB-V1 cells compared to the parental cell line, KB-3-1.

Previously we demonstrated that agents that reverse multidrug resistance also block the conversion of ${ }^{3} \mathrm{H}$-palmitatelabeled ceramide to ${ }^{3} \mathrm{H}-\mathrm{GC}$ (19). In the present study, tamoxifen inhibited $\mathrm{C}_{6}$-GC synthesis in $\mathrm{P}-\mathrm{gp} / \mathrm{on}$ and in $\mathrm{P}$-gp/off cells (Fig. 1B). Although P-gp levels in the P-gp/off cells were not detectable by our Western blot analysis, slight but detectable levels of P-gp were observed by Western blot analysis after the growth of HeLa P-gp/on cells for 4 days in the absence of colchicine and the presence of tetracycline (25). Therefore, the possibility exists that tamoxifen inhibition of $\mathrm{C}_{6}$-GC synthesis in P-gp/off cells was via residual, intracellular P-gp. It is clear however, that tamoxifen had no influence on $\mathrm{C}_{6}$-GC synthesis in KB-3-1 cells, and those are devoid of $\mathrm{P}-\mathrm{gp}$, but was strongly inhibitory in KB-3-1 cells.

In the cell-free $\mathrm{GCS}$ assays using $\mathrm{C}_{6}$-ceramide as the substrate, $\mathrm{C}_{6}$-GC production was not inhibited by tamoxifen in $\mathrm{P}$-gp/on preparations, whereas ethylenedioxy-P4 effectively blocked cell-free $\mathrm{C}_{6}$-GC synthesis. This established that tamoxifen did not inhibit GCS, that the levels of GCS activity were similar in the $\mathrm{P}$-gp/off and $\mathrm{P}$-gp/on cells, and that the accelerated conversion of $\mathrm{C}_{6}$-ceramide to $\mathrm{C}_{6}$-GC required the machinery of an intact cell.

Tamoxifen was the most potent inhibitor of $\mathrm{C}_{6}$-GC synthesis in the P-gp/on cells, where as cyclosporin A was less effective and verapamil had no influence. This could be related to differences in cell permeability or location of and affinity for distinct P-gp modulatory sites (27). All 3 antagonists were effective in limiting the vinblastine efflux in the P-gp/on cells.

A significant proportion of $\mathrm{P}-\mathrm{gp}$ is localized in the Golgi apparatus $(45,46)$. Given that the site of GC synthesis is localized to the cytoplasmic surface of the Golgi (47), this places Golgi-resident P-gp in a topologically opportune location to transport GC to the lumen where it is converted to lactosylceramide. In such a fashion, newly synthesized GC can be removed from GCS in conveyor-belt fashion. These ideas are supported by previous studies employing adriamycinresistant cancer cells and MDRl gene-transfected cancer cells (21) and by studies on acute myeloid leukemia (48). However, Halter et al (47) have demonstrated that newly synthesized GC enters 2 pathways, and that natural GC and the short- chain analogs exhibit dissimilar transport. Accordingly, the majority of P-gp lipid transport studies have been conducted employing short-chain analogs of GC (22-24).

The present observations are especially noteworthy in light of the role of GCS in multidrug resistance and in tempering ceramide cytotoxicity $(9,12,49)$. Related studies have shown that GCS and MDR1/MRP1 are often co-ordinately overexpressed $(14,15,33,50)$. In the present study, GCS mRNA levels and cell-free GCS activity were similar in the $\mathrm{P}$-gp/off and $\mathrm{P}$-gp/on cells. This suggests that $\mathrm{P}$-gp is the powerhouse behind $\mathrm{C}_{6}-\mathrm{GC}$ production in intact cells. The study of Sietsma et al (11) showed that the GCS inhibitor 1phenyl-2-decanoylamino-3-morpholino-1-propanol (PDMP) inhibited GCS and decreased the efflux of paclitaxel and vincristine in neuroblastoma, suggesting that GCS inhibitors also antagonize P-gp. In the present study, whereas ethylenedioxy-P4 effectively inhibited GCS in cell-free assays and in intact cells at $0.2 \mu \mathrm{M}$, it failed to enhance $\mathrm{C}_{6}$-ceramide cytotoxicity (Fig. 3). Ethylenedioxy-P4, a chemical cousin of 1-phenyl-2-hexadecanolamino-3-morpholino-1-propanol (PPMP) and PDMP, are the most potent of this group of inhibitors. GCS inhibition is routinely achieved in intact cells with PPMP and PDMP concentrations of 5-10 $\mu \mathrm{M}$. In light of our observations and the study of Sietsma et al (11), we suggest that GCS inhibitors such as PPMP at high concentrations have dual functions, namely inhibiting GCS and antagonizing P-gp. In a separate study on 2780AD multidrug-resistant ovarian cancer cells, we showed that whereas $0.2 \mu \mathrm{M}$ ethylenedioxy-P4 potently inhibited $\mathrm{C}_{6}$-GC synthesis, it failed to sensitize $2780 \mathrm{AD}$ cells to $\mathrm{C}_{6}$-ceramide. However, increasing the concentration of ethylenedioxy-P4 to $5.0 \mu \mathrm{M}$ effectively sensitized the cells to $\mathrm{C}_{6}$-ceramide (unpublished data). Therefore, the question arises, of whether it is better to inhibit GCS or antagonize P-gp in order to sensitize cells to ceramide-driven therapies. Whereas P-gp antagonists have met with limited clinical success, perhaps their function as regulators of ceramide metabolism could be a beneficial therapeutic indication.

\section{Acknowledgements}

This study was supported by the National Institute of General Medical Sciences (grant no. GM77391), the Associates for Breast and Prostate Cancer Studies (Santa Monica, CA), the Fashion Footwear Association of New York Charitable Foundation (New York, NY), and the National Cancer Institute (grant no. CA143755). We thank Matthew Bush for compiling the typescript and for creating the figures.

\section{References}

1. Lutzker SG and Levine AJ: Apoptosis and cancer chemotherapy. Cancer Treat Res 87: 345-356, 1996.

2. Gewirtz DA, Holt SE and Grant S (eds): Apoptosis, Senescence, and Cancer. 2nd edition. Humana Press Inc., Totowa, NJ, 2007.

3. Jaffrezou JP, Laurent G and Levade T: Ceramide in regulation of apoptosis. Implication in multitoxicant resistance. Subcell Biochem 36: 269-284, 2002.

4. Zheng W, Kollmeyer J, Symolon H, et al: Ceramides and other bioactive sphingolipid backbones in health and disease: lipidomic analysis, metabolism and roles in membrane structure, dynamics, signaling and autophagy. Biochim Biophys Acta 1758: 1864-1884, 2006. 
5. Saddoughi SA, Song P and Ogretmen B: Roles of bioactive sphingolipids in cancer biology and therapeutics. Subcell Biochem 49: 413-440, 2008.

6. Jarvis WD and Grant S: The role of ceramide in the cellular response to cytotoxic agents. Curr Opin Oncol 10: 552-559, 1998.

7. Gouaze-Andersson V and Cabot MC: Glycosphingolipids and drug resistance. Biochim Biophys Acta 1758: 2096-2103, 2006.

8. Lucci A, Han TY, Liu YY, Giuliano AE and Cabot MC: Modification of ceramide metabolism increases cancer cell sensitivity to cytotoxics. Int J Oncol 15: 541-546, 1999.

9. Liu YY, Han TY, Giuliano AE and Cabot MC: Ceramide glycosylation potentiates cellular multidrug resistance. FASEB J 15: 719-730, 2001

10. Deng W, Li R, Guerrera M, Liu Y and Ladisch S: Transfection of glucosylceramide synthase antisense inhibits mouse melanoma formation. Glycobiology 12: 145-152, 2002.

11. Sietsma H, Veldman RJ, Kolk D, et al: 1-phenyl-2decanoylamino-3-morpholino-1-propanol chemosensitizes neuroblastoma cells for taxol and vincristine. Clin Cancer Res 6: 942-948, 2000.

12. Olshefski RS and Ladisch S: Glucosylceramide synthase inhibition enhances vincristine-induced cytotoxicity. Int J Cancer 93: 131-138, 2001

13. Bleicher RJ and Cabot MC: Glucosylceramide synthase and apoptosis. Biochim Biophys Acta 1585: 172-178, 2002.

14. Lavie Y, Cao H, Bursten SL, Giuliano AE and Cabot MC: Accumulation of glucosylceramides in multidrug-resistant cancer cells. J Biol Chem 271: 19530-19536, 1996.

15. Lucci A, Cho WI, Han TY, Giuliano AE, Morton DL and Cabot MC: Glucosylceramide: a marker for multiple-drug resistant cancers. Anticancer Res 18: 475-480, 1998.

16. Bose R, Verheij M, Haimovitz-Friedman A, Scotto K, Fuks Z and Kolesnick R: Ceramide synthase mediates daunorubicininduced apoptosis: an alternative mechanism for generating death signals. Cell 82: 405-414, 1995.

17. Jaffrezou JP, Levade T, Bettaieb A, et al: Daunorubicin-induced apoptosis: triggering of ceramide generation through sphingomyelin hydrolysis. EMBO J 15: 2417-2424, 1996

18. Maurer BJ, Metelitsa LS, Seeger RC, Cabot MC and Reynolds CP: Increase of ceramide and induction of mixed apoptosis/ necrosis by N-(4-hydroxyphenyl)- retinamide in neuroblastoma cell lines. J Natl Cancer Inst 91: 1138-1146, 1999

19. Lavie Y, Cao H, Volner A, et al: Agents that reverse multidrug resistance, tamoxifen, verapamil, and cyclosporin $\mathrm{A}$, block glycosphingolipid metabolism by inhibiting ceramide glycosylation in human cancer cells. J Biol Chem 272: 1682-1687, 1997

20. De Rosa MF, Sillence D, Ackerley C and Lingwood C: Role of multiple drug resistance protein 1 in neutral but not acidic glycosphingolipid biosynthesis. J Biol Chem 279: 7867-7876, 2004.

21. Shabbits JA and Mayer LD: P-glycoprotein modulates ceramide-mediated sensitivity of human breast cancer cells to tubulin-binding anticancer drugs. Mol Cancer Ther 1: 205-213, 2002.

22. Eckford PD and Sharom FJ: The reconstituted P-glycoprotein multidrug transporter is a flippase for glucosylceramide and other simple glycosphingolipids. Biochem J 389: 517-526, 2005

23. van Helvoort A, Smith AJ, Sprong H, et al: MDR1 Pglycoprotein is a lipid translocase of broad specificity, while MDR3 P-glycoprotein specifically translocates phosphatidylcholine. Cell 87: 507-517, 1996.

24. Borst P, Zelcer $N$ and van Helvoort A: ABC transporters in lipid transport. Biochim Biophys Acta 1486: 128-144, 2000.

25. Aleman C, Annereau JP, Liang XJ, et al: P-glycoprotein, expressed in multidrug resistant cells, is not responsible for alterations in membrane fluidity or membrane potential. Cancer Res 63: 3084-3091, 2003.

26. Callaghan $\mathrm{R}$ and Higgins $\mathrm{CF}$ : Interaction of tamoxifen with the multidrug resistance P-glycoprotein. Br J Cancer 71: 294-299, 1995

27. Shao YM, Ayesh S and Stein WD: Mutually co-operative interactions between modulators of P-glycoprotein. Biochim Biophys Acta 1360: 30-38, 1997.

28. Bekaii-Saab TS, Perloff MD, Weemhoff JL, Greenblatt DJ and von Moltke LL: Interactions of tamoxifen, N-desmethyltamoxifen and 4-hydroxytamoxifen with P-glycoprotein and CYP3A. Biopharm Drug Dispos 25: 283-289, 2004
29. Bielawska A and Hannun YA: Preparation of radiolabeled ceramides and phosphosphingolipids. Methods Enzymol 311: 499-518, 2000

30. Lee L, Abe A and Shayman JA: Improved inhibitors of glucosylceramide synthase. J Biol Chem 274: 14662-14669, 1999.

31. Shen DW, Cardarelli C, Hwang J, et al: Multiple drug-resistant human KB carcinoma cells independently selected for highlevel resistance to colchicine, adriamycin, or vinblastine show changes in expression of specific proteins. J Biol Chem 261: $7762-7770,1986$

32. Gouaze V, Liu YY, Prickett CS, Yu JY, Giuliano AE and Cabot MC: Glucosylceramide synthase blockade downregulates $\mathrm{P}$-glycoprotein and resensitizes multidrug-resistant breast cancer cells to anticancer drugs. Cancer Res 65: 38613867, 2005.

33. Gouaze V, Yu JY, Bleicher RJ, et al: Overexpression of glucosylceramide synthase and P-glycoprotein in cancer cells selected for resistance to natural product chemotherapy. Mol Cancer Ther 3: 633-639, 2004.

34. Shukla GS and Radin NS: Glucosyceramide synthase of mouse kidney: further characterization with an improved assay method. Arch Biochem Biophys 283: 372-378, 1990.

35. Gouaze-Andersson V, Yu JY, Kreitenberg AJ, Bielawska A, Giuliano $\mathrm{AE}$ and Cabot MC: Ceramide and glucosylceramide upregulate expression of the multidrug resistance gene MDR1 in cancer cells. Biochim Biophys Acta 1771: 1407-1417, 2007.

36. Ohnishi A, Matsuo H, Yamada S, et al: Effect of furanocoumarin derivatives in grapefruit juice on the uptake of vinblastine by Caco- 2 cells and on the activity of cytochrome P450 3A4. Br J Pharmacol 130: 1369-1377, 2000.

37. Wang $\mathrm{H}$, Charles AG, Frankel AJ and Cabot MC: Increasing intracellular ceramide: an approach that enhances the cytotoxic response in prostate cancer cells. Urology 61: 1047-1052, 2003.

38. Cabot MC, Giuliano AE, Volner A and Han TY: Tamoxifen retards glycosphingolipid metabolism in human cancer cells. FEBS Lett 394: 129-131, 1996.

39. Nathan FE, Berd D, Sato T and Mastrangelo MJ: Paclitaxel and tamoxifen: An active regimen for patients with metastatic melanoma. Cancer 88: 79-87, 2000.

40. Rao US, Fine RL and Scarborough GA: Antiestrogens and steroid hormones: substrates of the human P-glycoprotein. Biochem Pharmacol 48: 287-292, 1994.

41. Tran MA, Smith CD, Kester M and Robertson GP: Combining nanoliposome ceramide with sorafenib synergistically inhibits melanoma and breast cancer cell survival to decrease tumor development. Clin Cancer Res 14: 3571- 3581, 2008.

42. Stover TC, Kim YS, Lowe TL and Kester M: Thermoresponsive and biodegradable linear-dendritic nanoparticles for targeted and sustained release of a pro-apoptotic drug. Biomaterials 29: 359-369, 2008.

43. Veldman RJ, Klappe K, Hinrichs J, et al: Altered sphingolipid metabolism in multidrug-resistant ovarian cancer cells is due to uncoupling of glycolipid biosynthesis in the Golgi apparatus. FASEB J 16: 1111-1113, 2002.

44. Dijkhuis AJ, Douwes J, Kamps W, Sietsma H and Kok JW: Differential expression of sphingolipids in P-glycoprotein or multidrug resistance-related protein 1 expressing human neuroblastoma cell lines. FEBS Lett 548: 28-32, 2003.

45. Molinari A, Cianfriglia M, Meschini S, Calcabrini A and Arancia G: P-glycoprotein expression in the Golgi apparatus of multidrug-resistant cells. Int J Cancer 59: 789-795, 1994.

46. Molinari A, Calcabrini A, Meschini S, et al: Subcellular detection and localization of the drug transporter P-glycoprotein in cultured tumor cells. Curr Protein Pept Sci 3: 653-670, 2002.

47. Halter D, Neumann S, van Dijk SM, et al: Pre- and post-Golgi translocation of glucosylceramide in glycosphingolipid synthesis. J Cell Biol 179: 101-115, 2007.

48. Turzanski J, Grundy M, Shang S, Russell N and Pallis M: Pglycoprotein is implicated in the inhibition of ceramide-induced apoptosis in TF- 1 acute myeloid leukemia cells by modulation of the glucosylceramide synthase pathway. Exp Hematol 33: $62-72,2005$.

49. Liu YY, Han TY, Giuliano AE and Cabot MC: Expression of glucosylceramide synthase, converting ceramide to glucosylceramide, confers adriamycin resistance in human breast cancer cells. J Biol Chem 274: 1140-1146, 1999.

50. Klappe K, Hinrichs JW, Kroesen BJ, Sietsma H and Kok JW: MRP1 and glucosylceramide are coordinately over expressed and enriched in rafts during multidrug resistance acquisition in colon cancer cells. Int J Cancer 110: 511-522, 2004. 